\title{
Asbestos exposure biomarkers in the follow-up of asbestos-exposed workers
}

\author{
Valentina PAOLUCCI ${ }^{1}$, Riccardo ROMEO ${ }^{2}$, Antonietta Gerardina SISINNI², \\ Giuseppina SCANCARELLO ${ }^{3}$, Luca VOLTERRANI ${ }^{4}$, Maria Antonietta MAZZEI ${ }^{4}$, \\ Lucio BARABESI ${ }^{5}$ and Pietro SARTORELLI ${ }^{6 *}$
}

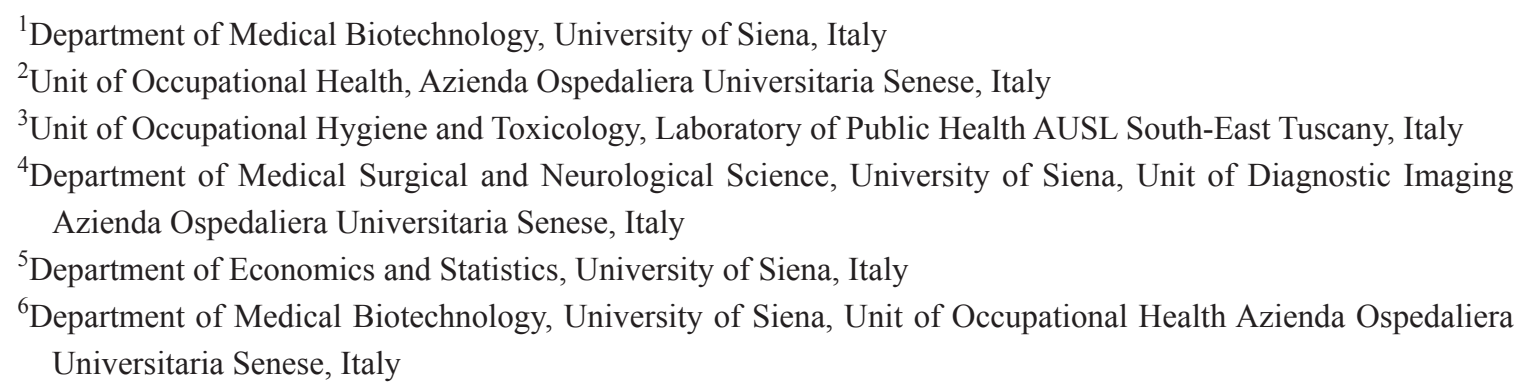

Received July 18, 2017 and accepted January 31, 2018

Published online in J-STAGE February 26, 2018

\begin{abstract}
Health surveillance of asbestos exposed workers should be stratified according to the exposure level. Unfortunately there is a lack of information regarding asbestos exposure in many working places and markers of asbestos exposure are often needed. The aim of the study was to assess the reliability of different dose and effect biomarkers in the follow up of asbestos-exposed workers. Mineralogical analysis of bronchoalveolar lavage fluid (BALF) as a biomarker of asbestos fibre burden was performed in a population of $\mathbf{3 0 7}$ male subjects occupationally exposed to asbestos. Using nonparametric statistical methods 8 variables were analyzed with respect to asbestosrelated diseases and working sectors. The existence of a relationship between serum soluble mesothelin-related peptides (SMRP) and asbestos exposure levels was also investigated. Concentrations of amphiboles, chrysotile and asbestos bodies in BALF were higher in patients with asbestosis as well as in railway industry workers. A correlation between the onset of non malignant asbestosrelated diseases and the levels of SMRP concentration was not found. This study confirms that fibre concentration in BALF may be considered as a reliable biomarker of previous asbestos exposure, whereas SMRP does not appear to be influenced by asbestos exposure levels.
\end{abstract}

Key words: Asbestos, Amphibole, Asbestosis, Biomarkers, Bronchoalveolar lavage, Mesothelin

\section{Introduction}

Health surveillance of asbestos exposed workers is

*To whom correspondence should be addressed.

E-mail: pietro.sartorelli@unisi.it

(C)2018 National Institute of Occupational Safety and Health mandatory in many countries. The Helsinki Declaration on Management and Elimination of Asbestos-Related Diseases adopted by the International Conference on Monitoring and Surveillance of Asbestos-Related Diseases stated that, in view of the long latency period of asbestosrelated diseases, health monitoring should continue after exposure has stopped, and among workers who may have changed job or retired ${ }^{1)}$. A general follow-up routine of 
asbestos-exposed workers should be stratified according to the intensity, latency and duration of exposure ${ }^{1)}$. A reliable work history could provide an useful measure of occupational asbestos exposure. However there is a lack of information regarding asbestos exposure (i.e. airborne fibre concentration and pattern of exposure) in many workplaces and biomarkers of asbestos exposure are often needed. Previous studies demonstrated that mineralogical analysis of bronchoalveolar lavage fluid (BALF) can represent a suitable method for the in vivo assessment of asbestos lung burden ${ }^{2-5}$. On the other hand cancer biomarkers like serum soluble mesothelin-related peptides (SMRP) were proposed for early diagnosis of neoplastic asbestos-related diseases ${ }^{6-9)}$ even if currently none of these seem sufficiently sensitive and specific for diagnostic or screening purposes ${ }^{1)}$. The aim of the study was to assess the reliability of mineralogical analysis of BALF as a marker of previous exposure to asbestos characterizing asbestos exposure in different working sectors and comparing exposure levels related to the different asbestos diseases. The existence of a possible relationship between SMRP and asbestos exposure levels was also investigated.

\section{Subjects and Methods}

\section{Subjects}

The occupationally exposed population consisted of 307 male workers (mean age $57 \mathrm{yr}$, range 41-81) hospitalized from 2007 to 2013 in the Occupational Medicine Unit of the University Hospital of Siena for suspected asbestosrelated diseases. With regard to the smoking habit 33\% out of them were non smokers, $48 \%$ former smokers with a mean of 17 packs/yr and $19 \%$ smokers with a mean of 22 packs/yr. According to the occupational history 8 main industrial activities were singled out: $20 \%$ railway industry (insulation removal and rolling stock production), $6 \%$ shipbuilding yards, $13 \%$ building industry, $11 \%$ metal foundry, $18 \%$ engineering industry, $8 \%$ transport (flight attendants, subway workers), $19 \%$ electric energy production, $5 \%$ other industries (typography, sugar refinery, glassware). A non professionally exposed population was randomly selected to determine the fibre concentration in BALF with respect to the values in occupationally exposed workers. Biological samples were obtained by a population of patients who from 2014 to 2015 underwent to a diagnostic fibreoptic bronchoscopy in the Pneumology Unit of the University Hospital of Siena for non malignant diseases.

Following current diagnostic criteria, chest X-ray and
High Resolution Computed Tomography (HRCT) were performed to evaluate the presence of asbestos-related diseases. Non malignant asbestos-related diseases were diagnosed following the American Thoracic Society (ATS) criteria ${ }^{10)}$. Moreover patients underwent pulmonary functional tests (PFTs), serum SMRP concentration dosage and bronchoscopy with mineralogical analysis of BALF to determine the asbestos lung burden. Considering the lag time from the first exposure to asbestos to the bronchoalveolar lavage (BAL) analysis, patients were split into three groups ( $\leq 20 \mathrm{yr}$, between 20 and $40 \mathrm{yr}$, between 40 and $60 \mathrm{yr}$ ). Taking into account the lag time between the last exposure to asbestos and BAL, they were divided into three groups ( $\leq 10 \mathrm{yr}$, between 10 and $20 \mathrm{yr}$, between 20 and $30 \mathrm{yr}$ ). PFTs were performed according to standard ATS 1987 and results were compared to CECA 1971 reference values. SMRP concentrations were determined by using Mesomark (CISbio International) according to the manifacturer's instructions.

With the regard to the sample of subjects non occupationally exposed to asbestos, according to the schedule approved by the Ethics Hospital Committee each patient before the examination provided the consent to take a sample of BALF for the mineralogical analysis and filled out a medical and professionally history questionnaire. On the bases of the results of the questionnaire patients with diagnosis of an interstitial lung disease, an occupational lung disease and an asbestos exposure were not enrolled. Following these criteria to avoid selection bias for exposition or pathology only 21 patients (17 male and 4 female, mean age $63 \mathrm{yr}$, range $37-81$ ) were selected. This group cannot be considered a statistical control group for the remarkable differences into the two populations due to the random selection.

\section{Chest CT}

HRCT examination consisted of a series (57 images) of $0.625 \mathrm{~mm}$ sections separated by $10 \mathrm{~mm}$ gaps, obtained in axial scanning mode $(0.625 / 4$ images 4 row, $1: 10 \mathrm{~mm}$ stop and shoot) using a 64 multidetector CT (VCT, General Electric Healthcare, Milwaukee, USA). The following parameters were used: subject position: prone; breathing instructions: suspended full inspiration; scanning mode: axial; display FOV: to encompass lungs at the largest anatomical location; interval: $10 \mathrm{~mm}$; collimation $0.625 \mathrm{~mm}$; reconstruction algorithm: high spatial frequency (bone plus); kV: 140 ; mAS: 330; time per tube rotation: $0.8 \mathrm{sec}$; intravenous contrast medium: none. Scanning was performed from the base to apex of the lung in order to avoid 
Table 1. Variables measured in the studied population of 307 male workers

\begin{tabular}{lcc}
\hline \multicolumn{1}{c}{ Variables } & Mean & Range \\
\hline Yr from the first asbestos exposure to bronchoscopy & 35 & $11-60$ \\
Yr from the last asbestos exposure to bronchoscopy & 19 & $1-46$ \\
Smoke habit (packs/yr) & 22 & $0-100$ \\
\% predicted FEV1 & 99 & $82-130$ \\
Serum SMRP concentration (nmol/l) & 0.8 & $0.7-4.6$ \\
BALF concentration of chrysotile (ff/ml BALF) & 962 & $\mathrm{ND}^{*-6480}$ \\
BALF concentration of amphiboles (ff/ml BALF) & 457 & $\mathrm{ND}^{*}-2077$ \\
BALF concentration of asbestos bodies (AB/ml BALF) & 10 & $\mathrm{ND}^{*-839}$ \\
\hline
\end{tabular}

*Not detectable.

diaphragmatic movements.

A standard reconstruction algorithm was also used to evaluate pleural alteration.

All the 307 CT examinations were retrospectively analysed by a Radiologist with more than $10 \mathrm{yr}$ of experience in thoracic imaging. The cases were randomly presented to the reader without any BALF data and clinical information. The CT examinations were evaluated for evidence of pleural plaques and parenchymal abnormalities according to The International Classification of High resolution CT for Occupational and Environmental Respiratory Diseases (ICOERD $)^{11)}$. A sum grade of $\geq 2-3$ bilateral irregular opacities in lower zones according to the reference film or bilateral honeycombing ( sum grade $\geq 2$ ) would be sufficient to represent fibrosis according to the ICOERD system $^{1}$. Subpleural curvilinear lines or dots, both findings of bronchiolar fibrosis at HRCT, were also considered as signs of asbestosis.

\section{Mineralogical analysis of BALF}

Asbestos bodies (AB) in BALF were counted with a phase contrast microscope at a magnification of $\times 250$ following the method described by De Vuyst ${ }^{12)}$. Ten $\mathrm{ml}$ of BALF were used for asbestos fibre counting with Scanning Electron Microscope (SEM) at a magnification of $\times 10,000$. The samples were filtered onto a $0.45 \mu \mathrm{m}$ Millipore filter. All reagents were pre-filtered onto a $0.22 \mu \mathrm{m}$ Millipore filter to avoid asbestos contamination. The sample was treated following the Dodson method ${ }^{13)}$. Only particles with an aspect ratio of 3:1 or more were counted not using the lower limits of length and diameter. The detection limit was $<160$ fibres/ml BALF.

\section{Statistical analysis}

In the studied population 8 variables were considered (Table 1) with respect to two factors (i.e. asbestos-related diseases and working sectors). For non malignant asbestos-related diseases workers were divided into 3 groups (i.e. pleural plaques, pleural plaques and asbestosis, no pathology), while considering working activities the studied population was split into 8 sectors (i.e. railway industry, shipbuilding yards, building industry, metal foundry, engineering industry, transports, electric energy production, other industries).

In a proper statistical setting, therefore we require for two separate MANOVA corresponding to each factor, with the aim of assessing if a different behaviour occurs with respect to the factors. Since some variables were discrete, an ordinary application of MANOVA testing based on Hotelling statistic was not suitable, because multivariate normality of the joint variable distribution does not hold. In this case, we have opted for a nonparametric approach to MANOVA. Thus the previously described ${ }^{4)}$ permutation testing procedure was applied which avoid the normality assumption and in addition allows for testing the items of the factor that eventually led to the refusal of the global null hypothesis (i.e. no effect of the factor) ${ }^{14)}$. In addition, for each sector the confidence intervals for the corresponding population means were computed by adopting the biascorrected and accelerated (BCa) bootstrap, as proposed by Efron ${ }^{15)}$. The bootstrap technique was adopted since a parametric approach does not seem suitable for modelling this data and hence a nonparametric technique is more appropriate. Moreover, the $\mathrm{BCa}$ bootstrap was chosen since it adjust for both bias and skewness in the bootstrap distribution and produces reasonably narrow intervals.

Statistical comparison between the results of the mineralogical analysis of BALF between the group of non asbestos exposed and professionally exposed patients was not possible because of the remarkable differences into the two groups (in particular regarding the sample size and genre). 


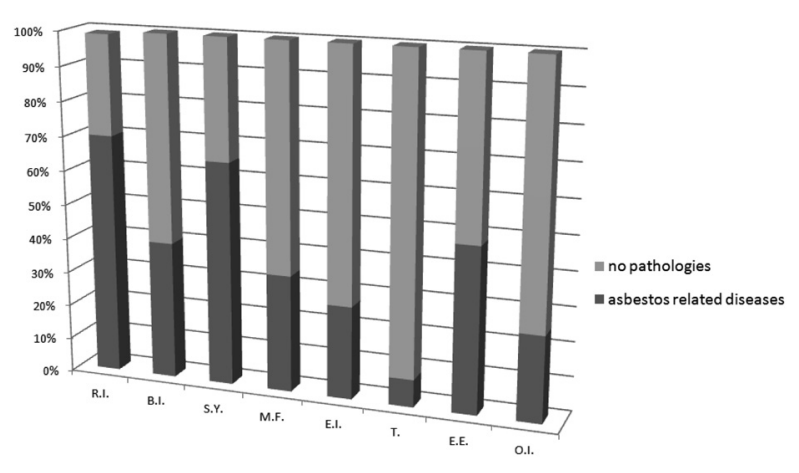

Fig. 1. Asbestos related diseases grouped for working sectors. R.I.: Railway industry; S.Y.: Shipbuilding Yards; B.I.: Building Industry; M.F.: Metal Foundry; E.I.: Engineering Industry; T.: Transports; E.E.: Electric Energy; O.I.: Other Industries.

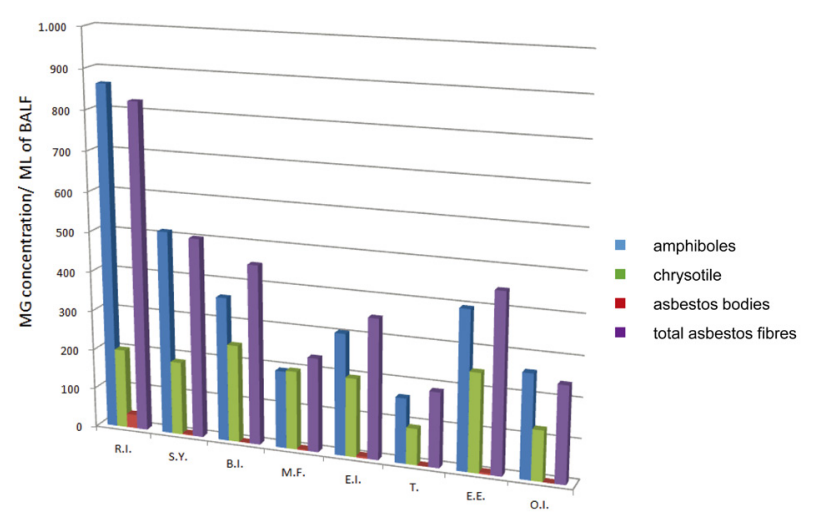

Fig. 2. Mean of concentration of amphiboles, chrysotile, asbestos bodies and total asbestos fibres/ml BALF in the professionally exposed workers grouped for working sectors.

R.I.: Railway industry; S.Y.: Shipbuilding Yards; B.I.: Building Industry; M.F.: Metal Foundry; E.I.: Engineering Industry; T.: Transports; E.E.: Electric Energy; O.I.: Other Industries.

Table 2. Confidence Intervals $95 \%$ (CIs) of concentration of amphiboles in BALF of exposed workers in different working sectors and in patients with asbestosis and pleural plaques. CIs are computed by adopting the bias-corrected and accelerated (BCa) bootstrap ${ }^{14)}$.

\begin{tabular}{lccc}
\hline & $\begin{array}{c}\text { Sample mean } \\
\text { (amphiboles/ml of BALF) }\end{array}$ & $\begin{array}{c}\text { CIs Lower limits } \\
\text { (amphiboles/ml of BALF) }\end{array}$ & $\begin{array}{c}\text { CIs Upper limits } \\
\text { (amphiboles/ml of BALF) }\end{array}$ \\
\hline Railway Industry & 863 & 714 & 1,046 \\
Building Industry & 512 & 406 & 650 \\
Shipbuilding Yards & 362 & 248 & 533 \\
Metal Foundry & 194 & 150 & 274 \\
Engineering Industry & 305 & 237 & 425 \\
Transport & 214 & 159 & 293 \\
Electric Energy Production & 397 & 318 & 563 \\
Other Industries & 260 & 166 & 360 \\
\hline Asbestosis and pleural plaques & 553 & 452 & 689 \\
\hline
\end{tabular}

\section{Results}

On the basis of the radiological and clinical study in 132 patients $(43 \%)$ a non malignant asbestos related disease was diagnosed. 85 of them had pleural plaques, 2 subjects were affected by asbestosis and in 45 cases pleural plaques and asbestosis were both present. In Fig. 1 the distribution of asbestos diseases divided for working sectors is shown.

Figure 2 shows the concentrations of amphiboles, chrysotile and total asbestos fibres in BALF of professionally exposed workers grouped for working sectors. The highest percentage of asbestos-related diseases was found in the railway industry according to the upper average of asbestos fibres and $\mathrm{AB}$ concentrations in BALF. At the same time the transport workers, who have not asbestos diseases, presented the lowest concentration in the BALF of all biomarkers.

Statistical analysis applied to the different groups of asbestos diseases rejected the overall null hypothesis, and the rejection was due mainly to the lag time from the last exposure and the concentration of amphiboles in BALF $(p$-value $<0.001)$ and in a lesser extent to chrysotile $(p$-value $=0.04)$ and AB concentration in BALF ( $p$-value $=0.02)$.

The same analysis when was applied to the different working sectors rejected the overall null hypothesis ( $p$-value $<0.001)$. Also in this case the rejection was mainly due to the years from the last asbestos exposure ( $p$-value $<0.001)$ and to the concentration of amphiboles in BALF $(p$-value $<0.001)$ and in a lesser extent to the chrysotile concentration in BALF ( $p$-value $=0.03$ ).

Serum SMRP concentration does not vary significantly 
between the different groups of workers divided by pathology and occupational sector.

Fibre concentration in BALF of patients non occupationally exposed to asbestos in all cases was lower than the detection limit of the method.

Table 2 shows the Confidence Intervals 95\% (CIs) of concentration of amphiboles in BALF of exposed workers for each working sector and in patients with asbestosis and pleural plaques.

\section{Discussion}

Asbestos exposure biomarkers values (i.e. concentrations of amphiboles, chrysotile and $\mathrm{AB}$ in BALF) were higher in patients with asbestosis as well as in railway industry workers. Even if the population of non asbestosexposed patients should not be considered as a control group, the negativity of fibre concentration in BALF in all cases confirms a good specificity of the analysis. According to previous studies ${ }^{2-4)}$ the results confirm also that fibre concentration in BALF can be considered as a reliable biomarker of previous asbestos exposure even after many years from the end of exposure. Statistical analysis shows that there is a relationship between higher concentration of amphiboles in BALF and the onset of non malignant asbestos-related diseases. This is particularly evident considering the highest percentage of asbestos diseases in the railway industry and the lowest one in transport sector, corresponding respectively to the highest and lowest Mean of concentration of amphiboles observed in BALF. A comprehensive review on the pathogenesis of asbestos fibrosis pointed out that the lung burden of amphiboles is the main variable in the dose-response relation between the intensity of asbestos exposure and the severity of the asbestosis ${ }^{16)}$. Therefore exposures quantitatively similar but qualitatively different could play a different role in asbestos lung injury and the pattern of exposure seems as important as the intensity of exposure. We did not investigate the usefulness of the fibre concentration in BALF in the diagnosis of malignant mesothelioma (MM). Actually in literature there is a lack of data on this important issue. There is a number of papers concerning concentrations of $\mathrm{AB}$ and fibre in the lung tissue of patients with $\mathrm{MM}$ that demonstrated a high pulmonary burden of asbestos in the presence of a history of asbestos exposure, even many years after the cessation of exposure ${ }^{17,18)}$. However, in the absence of specific data, it is not possible by similarity to transfer this information to the mineralogical examination of the BALF. In any case it is important to note that a "negative" non-effect outcome of the mineralogical analysis of BALF or lung tissue excludes neither potential past exposure nor the likelihood of asbestos-related disease to develop, while with "positive" results the probability of a serious health consequence is increased ${ }^{19-21)}$.

The second significant variable with respect to working sectors and asbestos diseases is the lag time from the last asbestos exposure, that represents the "wash-out time". In the railway industry the mean time from the last asbestos exposure is over $30 \mathrm{yr}$. Considering other sectors such as building industry and energy production, the prevalence of asbestos-related diseases is much lower compared to amphibole concentration levels, but in those cases the time shift from the last exposure is less than $20 \mathrm{yr}$. Therefore a follow-up of this populations for the next $10 \mathrm{yr}$ is needed in order to a quantitative comparison of asbestos diseases.

With regard to $\mathrm{AB}$ concentration in BALF results confirm that, as a marker of asbestos exposure, it has good specificity but a less sensibility and a poor correlation with chrysotile exposure ${ }^{4)}$. Thus there may be cases of chrysotile-induced asbestosis without increased levels of $\mathrm{AB}$ as may be others without increased chrysotile lung burden because of the its higher clearence rates in comparison to amphiboles ${ }^{1)}$.

In workers of railway industry, building industry, shipbuilding yards and electric energy production the CIs upper limit of amphibole concentration in BALF was higher than the lower limit observed in patients with asbestosis. In the building and railway industries was found a lung burden of amphiboles respectively similar and greater to that observed in patients suffering from asbestosis.

The other variables do not differ between healthy and pathologic workers. According to a previous study ${ }^{22)}$ there is no significant difference of serum SMRP concentration in workers with asbestos-related diseases and in healthy ones. Moreover SMRP levels do not vary between different working sectors. Therefore this biomarker does not appear to be influenced by asbestos exposure levels.

\section{Acknowledgment}

We thank Dr. Giuseppe Marcianò (Pneumology Unit of the University Hospital of Siena) for his kind collaboration.

\section{References}

1) Wolff H, Vehmas T, Oksa P, Rantanen J, Vainio H (2015) Asbestos, asbestosis, and cancer, the Helsinki criteria for 
diagnosis and attribution 2014: recommendations. Scand J Work Environ Health 41, 5-15. [Medline] [CrossRef]

2) Sartorelli P, Scancarello G, Romeo R, Marcianò G, Rottoli P, Arcangeli G, Palmi S (2001) Asbestos exposure assessment by mineralogical analysis of bronchoalveolar lavage fluid. J Occup Environ Med 43, 872-81. [Medline] [CrossRef]

3) Romeo R, Scancarello G, Cassano P, Cioni F, Bacaloni A, Sartorelli P (2004) [Assessment of asbestos exposure via mineralogical analysis of bronchoalveolar lavage fluid]. Med Lav 95, 17-31 (in Italian). [Medline]

4) Sartorelli P, Romeo R, Scancarello G, Montomoli L, Muzzupappa C, Barabesi L (2007) Measurement of asbestos fibre concentrations in fluid of repeated brochoalveolar lavages of exposed workers. Ann Occup Hyg 51, 495-500. [Medline]

5) Sartorelli P, Romeo R, Pescaglini M, Serio AC, Banchi B, Scancarello G (2010) Determination of asbestos fiber concentration in brochoalveolar lavage fluid: comparison between trasmission and scansion electron microscopy. G Ital Med Lav Ergon 32 Suppl 2, 290-1.

6) Robinson BWS, Creaney J, Lake R, Nowak A, Musk AW, de Klerk N, Winzell P, Hellstrom KE, Hellstrom I (2003) Mesothelin-family proteins and diagnosis of mesothelioma. Lancet 362, 1612-6. [Medline] [CrossRef]

7) Beyer HL, Geschwindt RD, Glover CL, Tran L, Hellstrom I, Hellstrom KE, Miller MC, Verch T, Allard WJ, Pass HI, Sardesai NY (2007) MESOMARK: a potential test for malignant pleural mesothelioma. Clin Chem 53, 666-72. [Medline] [CrossRef]

8) Scherpereel A, Grigoriu B, Conti M, Gey T, Grégoire M, Copin MC, Devos P, Chahine B, Porte H, Lassalle P (2006) Soluble mesothelin-related peptides in the diagnosis of malignant pleural mesothelioma. Am J Respir Crit Care Med 173, 1155-60. [Medline] [CrossRef]

9) Cristaudo A, Foddis R, Vivaldi A, Guglielmi G, Dipalma N, Filiberti R, Neri M, Ceppi M, Paganuzzi M, Ivaldi GP, Mencoboni M, Canessa PA, Ambrosino N, Chella A, Mutti L, Puntoni R (2007) Clinical significance of serum mesothelin in patients with mesothelioma and lung cancer. Clin Cancer Res 13, 5076-81. [Medline] [CrossRef]

10) American Thoracic Society (2004) Diagnosis and initial management of non malignant diseases related to asbestos. Am J Resp Crit Care 170, 691-715. [CrossRef]

11) Suganuma N, Kusaka Y, Hering KG, Vehmas T, Kraus T, Arakawa H, Parker JE, Kivisaari L, Letourneux M, Gevenois PA, Tuengerthal S, Crane MD, Shida H, Akira M, Henry DA, Nakajima Y, Hiraga Y, Itoh H, Hosoda Y (2009) Reliability of the proposed international classification of high-resolution computed tomography for occupational and environmental respiratory diseases. J Occup Health 51, 210-22 [CrossRef]. [Medline]

12) De Vuyst P, Dumortier P, Moulin E, Yourassowsky N, Yernault JC (1987) Diagnostic value of asbestos bodies in bronchoalveolar lavage fluid. Am Rev Respir Dis 136, 1219-24. [Medline] [CrossRef]

13) Dodson RF, Garcia JG, O'Sullivan M, Corn C, Levin JL, Griffith DE, Kronenberg RS (1991) The usefulness of bronchoalveolar lavage in identifying past occupational exposure to asbestos: a light and electron microscopy study. Am J Ind Med 19, 619-28. [Medline] [CrossRef]

14) Pesarin F, Salmaso L (2010) Permutation tests for complex data: theory, applications and software. Wiley, New York.

15) Efron B (1987) Better bootstrap confidence intervals. J Am Stat Assoc 82, 171-85. [CrossRef]

16) Mossman BT, Lippmann M, Hesterberg TW, Kelsey KT, Barchowsky A, Bonner JC (2011) Pulmonary endpoints (lung carcinomas and asbestosis) following inhalation exposure to asbestos. J Toxicol Environ Health B Crit Rev 14, 76-121. [Medline] [CrossRef]

17) Merler E, Somigliana A, Girardi P, Barbieri PG (2017) Residual fibre lung burden among patients with pleural mesothelioma who have been occupationally exposed to asbestos. Occup Environ Med 74, 218-27 [CrossRef]. [Medline]

18) Feder IS, Tischoff I, Theile A, Schmitz I, Merget R, Tannapfel A (2017) The asbestos fibre burden in human lungs: new insights into the chrysotile debate. Eur Respir J 49, 1602534. [Medline] [CrossRef]

19) Roggli VL, Gibbs AR, Attanoos R, Churg A, Popper H, Cagle P, Corrin B, Franks TJ, Galateau-Salle F, Galvin J, Hasleton PS, Henderson DW, Honma K (2010) Pathology of asbestosis - an update of the diagnostic criteria: report of the asbestosis committee of the college of american pathologists and pulmonary pathology society. Arch Pathol Lab Med 134, 462-80. [Medline]

20) Vainio H (2015) Epidemics of asbestos-related diseasessomething old, something new. Scand J Work Environ Health 41, 1-4. [Medline] [CrossRef]

21) Nuyts V, Vanhooren H, Begyn S, Nackaerts K, Nemery B (2017) Asbestos bodies in bronchoalveolar lavage in the 21st century: a time-trend analysis in a clinical population. Occup Environ Med 74, 59-65. [Medline] [CrossRef]

22) Pescaglini M, Romeo R, Serio AC, Taccioli A, Sartorelli $P$ (2009) Serum-soluble mesothelin family proteins (SMRP) assay in asbestos-exposed workers within a health surveillance program. G Ital Med Lav Ergon 31 Suppl 2, $210-1$. 